ARTICLE

\title{
Equi-size nesting of Platonic and Archimedean metal-organic polyhedra into a twin capsid
}

\author{
Hongmei Gan ${ }^{1}, \mathrm{Na} X \mathrm{u}^{1}$, Chao Qin ${ }^{1}$, Chunyi Sun (1) ${ }^{1}$, Xinlong Wang (i]) ${ }^{1 凶} \&$ Zhongmin Su $^{1}$
}

Inspired by the structures of virus capsids, chemists have long pursued the synthesis of their artificial molecular counterparts through self-assembly. Building nanoscale hierarchical structures to simulate double-shell virus capsids is believed to be a daunting challenge in supramolecular chemistry. Here, we report a double-shell cage wherein two independent metal-organic polyhedra featuring Platonic and Archimedean solids are nested together. The inner $(3.2 \mathrm{~nm})$ and outer $(3.3 \mathrm{~nm})$ shells do not follow the traditional "small vs. large" pattern, but are basically of the same size. Furthermore, the assembly of the inner and outer shells is based on supramolecular recognition, a behavior analogous to the assembly principle found in double-shell viruses. These two unique nested characteristics provide a new model for Matryoshka-type assemblies. The inner cage can be isolated individually and proves to be a potential molecular receptor to selectively trap guest molecules.

\footnotetext{
${ }^{1}$ National \& Local United Engineering Laboratory for Power Batteries, Key Laboratory of Polyoxometalate Science of Ministry of Education, Northeast Normal University, Changchun, Jilin, China. ${ }^{凶}$ email: wangxl824@nenu.edu.cn
} 
$\mathrm{T}$ he attractiveness of molecular coordination cages ${ }^{1-5}$, sometimes termed as metal-organic polyhedra $(\mathrm{MOPs})^{6}$, lies in their structural resemblance to natural living organisms, for example, the icosahedron is reminiscent of spherical viruses ${ }^{7,8}$ and rhombic dodecahedron is akin to ferritin ${ }^{9}$. Therefore, the research on these capsid polyhedral structures could help scientists to design and develop more rational antiviral strategies. Currently, self-assembly of metal-organic capsules by taking advantage of the rational and judicious selection of reaction components has been well-established, represented by the prominent work of Stang ${ }^{10,11}$ and Fujita and co-workers ${ }^{12-14}$; however, it is still a daunting challenge for chemists to produce hierarchical polyhedral capsids that consist of well-defined subshells similar to the onion-type arrangements.

Double-shell architectures are special in chemistry and rare in non-biological chemistry although frequently occur naturally in the form of spherical virus capsids ${ }^{15-17}$. Artificial synthesis of such hierarchically organized cage-within-cage structures should be able to further our understanding of the interaction behavior between inside and outside shells of virus capsids at the molecular scale. And equally importantly, it may provide a new class of functional supramolecular hosts. However, progress in this area has been frustrated by the absence of the underlying assembly principles. The design synthesis of double-shell architectures is still an elusive target for researchers. Unlike single-wall molecular aggregates ${ }^{18-21}$, the intrinsic structural particularity of doubleshell MOPs sets a higher requirement for building components, especially for organic ligands in that how to reinforce structural subdivision is a key factor to be considered in the process of selfassembly. Because of this, with the exception of a few sporadic reports on metal-organic frameworks (MOFs) containing doubleshell subunits so far ${ }^{22-26}$, double-shell macromolecular cages are much more rarely observed in the literature, with Pd-involved self-assembly being the commonest. This series of sphere-insphere assemblies with a general formula of $\mathrm{Pd}_{24} \mathrm{~L}_{24}$ are pioneered by Fujita and colleagues by selecting a tethered ligand on purpose ${ }^{27}$, and are developed in the groups of $\mathrm{Li}^{28}$ and Mukherjee ${ }^{29}$ by precise mapping of ligand coordination sites. More recently, Schmitt et al. ${ }^{30}$ have reported the synthesis of ultra-large coordination cages that are composed of multiple smaller sub-cages. The basic attributes of these existing cases have been investigated and schematically shown in Fig. 1. First, the inner and outer cages are not absolutely independent but interconnected by covalent metal-ligand contacts. This behavior is different from what has been seen in living systems wherein only supramolecular interactions exist between the shells. Second, the inner and outer cages, irrespective of their geometrical configuration, always have
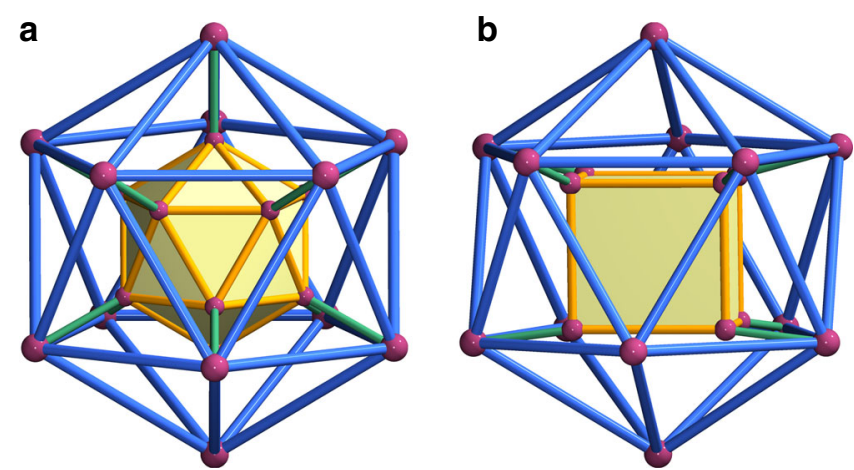

Fig. 1 Two known endohedral models. The inner (marked in orange) and outer (marked in blue) cages of different sizes, whether they have the same (a) or different (b) geometry, are interconnected by covalent linkages (marked in green). an obvious difference in size, the smaller inside, and the larger outside. This, then, raises the crucial question of whether there may exist entirely new nesting topologies that do not comply with the aforesaid rules. If we can find such an example, it will provide a valuable structural paradigm for this infant family, and more importantly, such a finding might shed light on the hidden nesting mechanism that guides the synthesis of the highly complicated structures, thus taking an important step towards a closer mimic of the complex biological self-assembly.

Our serendipitous experimental outcome addresses this issue. Herein we present an elegant double-shell cage, which was formulated as $\left(\mathrm{NH}_{2} \mathrm{Me}_{2}\right)_{24}\left\{\left[\left(\mathrm{~V}_{5} \mathrm{O}_{9} \mathrm{Cl}\right)_{6}(\mathrm{TATB})_{8}\right]\left[\mathrm{V}_{12} \mathrm{O}_{12}(\mathrm{TATB})_{8}\right.\right.$ $\left.\left.\left(\mathrm{HSO}_{4}\right)_{12}\right]\right\} \cdot\left(\mathrm{CH}_{3} \mathrm{OH}\right)_{16}$ by elemental microanalysis, thermogravimetric analysis (TGA) (Supplementary Fig. 1), and a singlecrystal X-ray diffraction study (hereafter $\mathbf{1}$ for short, $\mathrm{H}_{3} \mathrm{TATB}=$ 4,4'4"-s-triazine-2,4,6-triyl-tribenzoic acid, $\mathrm{DMF}=\mathrm{N}, \mathrm{N}$-dimethylformamide). In $\mathbf{1}$, a $\left[\left(\mathrm{V}_{5} \mathrm{O}_{9} \mathrm{Cl}\right]_{6}(\mathrm{TATB})_{8}\right]$ octahedron perfectly nests in a $\left[\mathrm{V}_{12} \mathrm{O}_{12}(\mathrm{TATB})_{8}\left(\mathrm{HSO}_{4}\right)_{12}\right]$ cuboctahedron. The double-shell MOP exhibits two distinguishing characteristics. One is that the assembly of the inner and outer shells is guided by non-covalent interactions (herein refers to $\pi \ldots \pi$ supramolecular recognition), a manner reminiscent of the analogous assembly principle found in double-shell virus capsids; the other is that the nesting occurs in two nearly equi-sized polyhedra, one $32 \AA$ and the other $33 \AA-$ an almost impossible case in a normal sense, making the endohedral degree to the extreme. What is even more interesting is that the inner polyoxovanadate-based cage, namely, $\left[\left(\mathrm{V}_{5} \mathrm{O}_{9} \mathrm{Cl}\right)_{6}(\mathrm{TATB})_{8}\right]^{12-}(\mathbf{1 a})$, has been isolated individually. 1 and 1 a can selectively adsorb cationic dye molecules due to their anionic nature. In addition, $\mathbf{1 a}$ is capable of serving as a supramolecular receptor to selectively encapsulate guest molecules $\left(\mathrm{C}_{60}\right.$ and anthracene) owing to its large void space. Temperaturedependent magnetic susceptibilities for $\mathbf{1}$ and $\mathbf{1 a}$ were also studied, and the weak ferromagnetic coupling interactions within the double-shell cage or the independent interior cage have been observed.

\section{Results}

Synthesis and description of double-shell cage. Compound 1 was synthesized by the solvothermal reaction of $\mathrm{NaVO}_{3}, \mathrm{VOSO}_{4}$, $\mathrm{VCl}_{3}$ and $\mathrm{H}_{3} \mathrm{TATB}$ in DMF: $\mathrm{CH}_{3} \mathrm{CN}: \mathrm{CH}_{3} \mathrm{OH}(4: 1: 1 \mathrm{v} / \mathrm{v})$ at $130^{\circ} \mathrm{C}$ for $48 \mathrm{~h}$ (see the "Methods" section for a detailed synthesis procedure). The sensitivity of the synthesis to temperature needs to be considered; the product is not available below $130^{\circ} \mathrm{C}$, indicating that $\mathbf{1}$ is the thermodynamically favored outcome. The phase purity of the bulk products was confirmed by comparison of the observed and calculated powder X-ray diffraction (PXRD) patterns (Supplementary Fig. 2). Single-crystal X-ray diffraction analysis revealed that $\mathbf{1}$ crystallized in the tetragonal space group $I 4 / m$ (Supplementary Table 1 ). The anionic moiety is composed of two independent coordination cages with the formula $\left[\left(\mathrm{V}_{5} \mathrm{O}_{9} \mathrm{Cl}\right)_{6}(\mathrm{TATB})_{8}\right]\left[\mathrm{V}_{12}(\mathrm{TATB})_{8}\left(\mathrm{HSO}_{4}\right)_{12}\right]^{24-}$. The 24 negative charges are balanced by twenty-four dimethylamine cations $\left(\mathrm{H}_{2} \mathrm{NMe}_{2}\right)^{+}$(the byproduct of in situ decomposition of DMF molecules). The existence of $\left(\mathrm{H}_{2} \mathrm{NMe}_{2}\right)^{+}$is confirmed by IR spectrum (Supplementary Fig. 3). Scanning electron microscopy with energy-dispersive X-ray spectroscopy (SEM-EDX, Supplementary Fig. 4) and X-ray photoelectron spectroscopy (XPS) (Supplementary Fig. 5,6) confirmed the sample purity and the oxidation states of vanadium atoms. Overall bond valence sum $(B V S)^{31}$ calculations indicate that $V$ cations exhibit $+4 /+5$ oxidation states, respectively (Supplementary Table 2), which is consistent with the results of XPS spectra (Supplementary Fig. 6).

The inner cage is a polyoxovanadate-based metal-organic octahedron, $\left.\left[\mathrm{V}_{5} \mathrm{O}_{9} \mathrm{Cl}\right)_{6}(\mathrm{TATB})_{8}\right]^{12-}$, constructed from $\left\{\mathrm{V}_{5} \mathrm{O}_{9} \mathrm{Cl}\right\}$ 

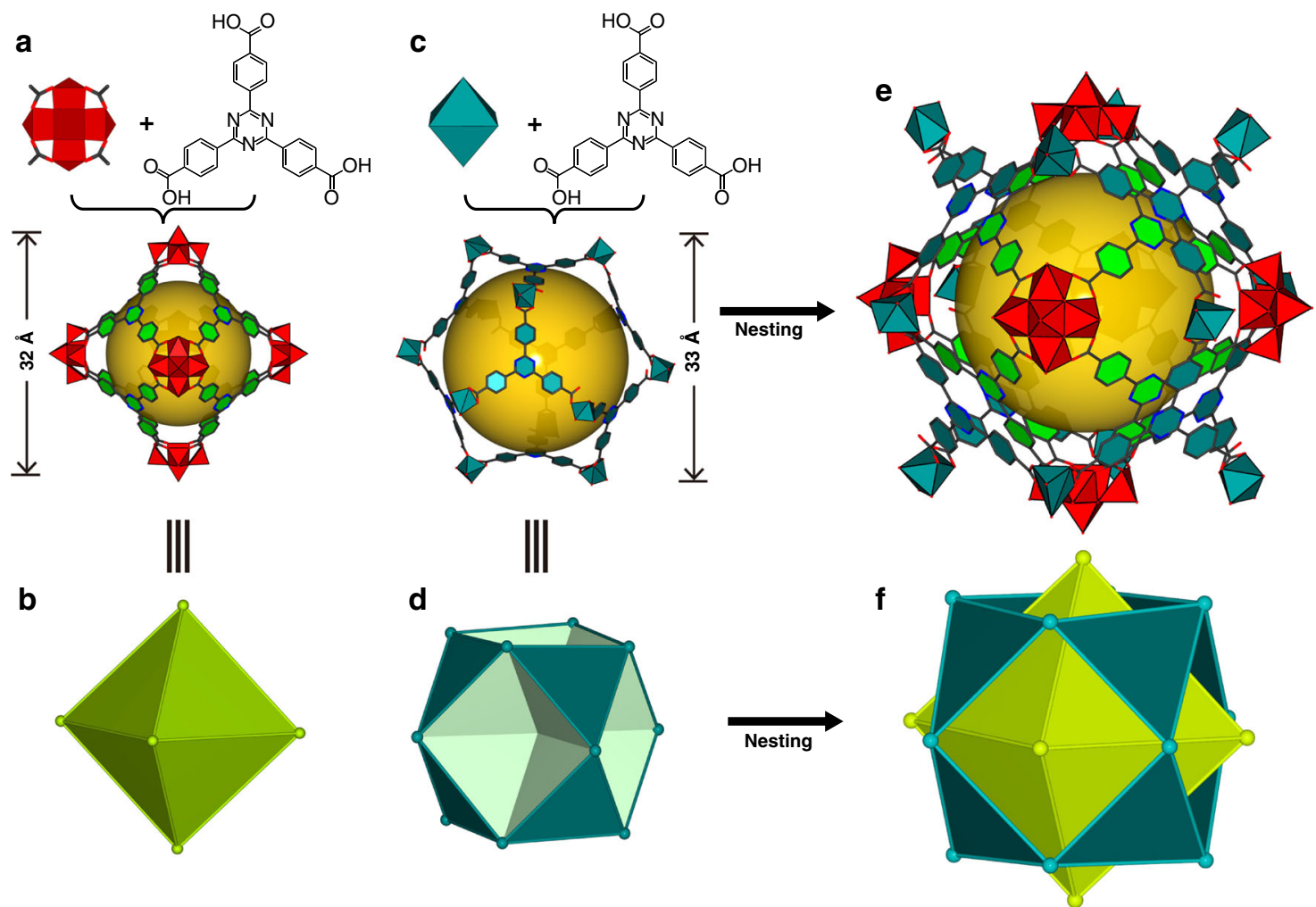

Fig. 2 The double-shell structure of 1. a The structure of the inner cage constructed by $\left\{\mathrm{V}_{5} \mathrm{O}_{9} \mathrm{Cl}\right\}$ clusters and TATB ligands. The yellow ball placed in the structure indicates the interior space of the cage. $\mathbf{b}$ The polyhedral model of the inner cage is represented by an octahedron, in which $\left\{\mathrm{V}_{5} \mathrm{O}_{9} \mathrm{Cl}\right\}$ clusters are chosen as vertices of the polyhedron and TATB ligands act as faces of a trigon. $\mathbf{c}$ The structure of the outer cage constructed by $V$ atoms and TATB ligands. d The polyhedral model of the outer cage is represented by a cuboctahedron, in which $V$ atoms are chosen as vertices of the polyhedron and TATB ligands act as faces of a trigon. $\mathbf{e}$ The real nested structure of the inner and outer cages. $\mathbf{f}$ Schematic representation of the nesting between Archimedean and Platonic polyhedra.

clusters and TATB ligands (Fig. 2a, Supplementary Fig. 7a). The $\left\{\mathrm{V}_{5} \mathrm{O}_{9} \mathrm{Cl}\right\}$ cluster, as a concave secondary building block, consists of an apical vanadium atom $(+5)$ and four basal plane vanadium atoms $(+4)$ bridged by four $\mu_{3}-\mathrm{O}$ atoms (Supplementary Fig. $7 \mathrm{~b}$ ) with the $\mathrm{V}-\mathrm{O}$ bond lengths ranging from 1.577 (8) to 2.021 (5) $\AA$ A. Moreover, the IR spectrum of the double-shell cage shows the characteristic $\mathrm{V}=\mathrm{O}$ band in the range of $950-990 \mathrm{~cm}^{-1}$ (Supplementary Fig. 3). Each $\left\{\mathrm{V}_{5} \mathrm{O}_{9} \mathrm{Cl}\right\}$ cluster is coordinated with four carboxylate ligands, generating a bowl-shaped motif (Supplementary Fig. 8). Six such concave units are further bridged by eight TATB ligands, thereby affording an octahedron that belongs to one of Platonic solids (Fig. 2b) with the face symbol $\left[3^{8}\right]$. The TATB ligands act as the triangular faces, and the $\left\{\mathrm{V}_{5} \mathrm{O}_{9} \mathrm{Cl}\right\}$ clusters act as the vertices of the octahedron. The outer diameter of the octahedron is approximately $3.2 \mathrm{~nm}$ as measured by the longest distance between the outermost oxygen atoms of antipodal vertices. To indicate the interior space, a yellow ball is placed in the cavity ${ }^{32}$ by Diamond program ${ }^{33}$ (Fig. 2a), whose diameter is of ca. $1.9 \mathrm{~nm}$ based on the distance between the antipodal $\mathrm{Cl}$ ions.

The outer cage, $\left[\mathrm{V}_{12} \mathrm{O}_{12}(\mathrm{TATB})_{8}\left(\mathrm{HSO}_{4}\right)_{12}\right]^{12-}$, is constructed by eight TATB ligands and twelve vanadium atoms (Fig. $2 \mathrm{c}$ ), whose topology is best described as a cuboctahedron, one of Archimedean solids with $F=14, E=24, V=12$ (F: Face, $E$ : Edge, $V$ : vertex) (Fig. 2d). The $\mathrm{V} \cdots \mathrm{V}$ distances along the edges of the polyhedron are in the range of $16.376(6)-16.677(6) \AA$. The largest cross-sectional diameter of this cuboctahedron is about $3.3 \mathrm{~nm}$ (metal to metal), and the inner diameter represented by the yellow sphere (Fig. 2c) is of ca. $2.6 \mathrm{~nm}$ based on the distance between the antipodal triazine rings. It is noted that the coordination environment of the outer $\mathrm{V}$ ions is different from that of the inner ones. Each $\mathrm{V}^{\mathrm{IV}}$ center is coordinated by two TATB ligands and a sulfite, with the $\mathrm{V}-\mathrm{O}$ bond lengths ranging from $1.60(2)$ to $2.431(11) \AA$.

In view of the fact that the inner and outer cages are very close in size, it seems nearly impossible to generate a Matryoshka-type structure at first glance. Is there any specific factor that makes such a case occur? A deeper probe into the geometric relationship of regular polyhedra might be able to give us a lead. As we know, Archimedean polyhedra are derived from Platonic polyhedra by truncated operation. Consequently, a cuboctahedron is created by cutting away six corners of an octahedron, while preserving their own symmetry (both $O_{h}$ point-group symmetry). Following the above operation, in the current situation, if we restore the cuboctahedron into its precursor polyhedron, a larger octahedron with a diameter of $4.7 \mathrm{~nm}$ can be obtained that is sufficiently large to accommodate an octahedron of $3.2 \mathrm{~nm}$. As a result, it is theoretically possible for two polyhedra with approximate size to be nested. The following question is what kind of arrangement the two cages take, that is to say, how do they interact with each other to achieve the ultimate Matryoshka-type architecture? To generate nesting, one feasible strategy is that the six vertices of the inner octahedron thread out from the vacant square polygons of the outer cuboctahedron, as shown in Fig. 2e. Such an intelligent arrangement fashion results in the fact that the TATB ligands of the inner octahedron are nearly parallel with TATB ligands of the outer cuboctahedron, the dihedral angle being $0.972(1)^{\circ}$ (Figs. 2f, $3 a$ ). Because most of the ring plane areas overlap each other, the face-to-face distance between two triazine rings is of 3.292(2) $\AA$ and the centroid-centroid distance is of 3.306(2) $\AA$ (Fig. 3a). 


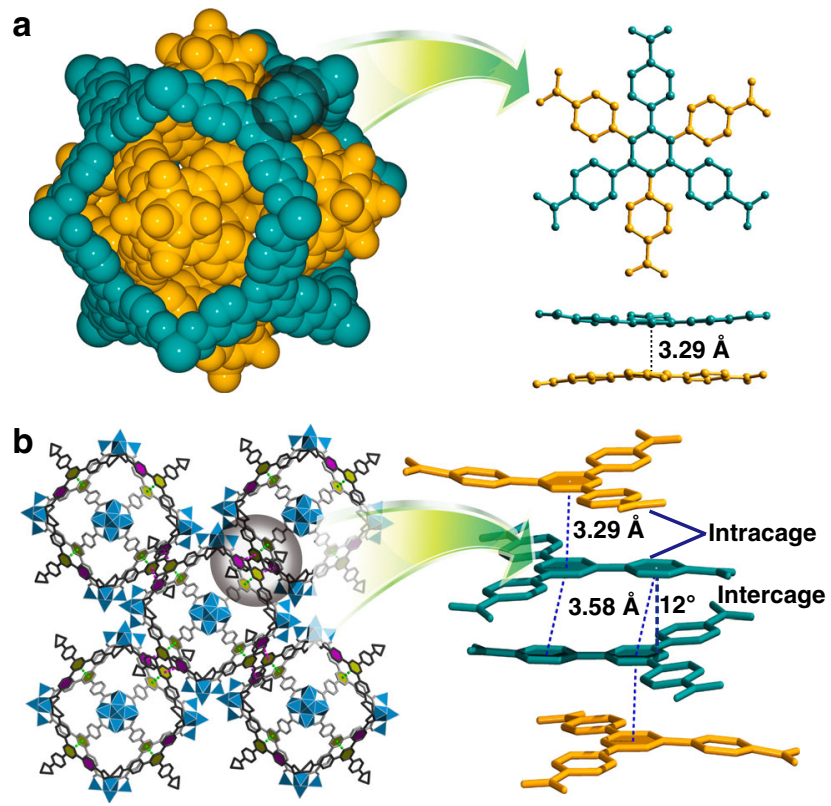

Fig. 3 Supramolecular interactions of 1. a A face-to-face $\pi-\pi$ interaction between the inner and outer cages, where most of the ring-plane area overlaps. Atoms of the inner and outer cages are marked in orange and cyan, respectively. $\mathbf{b} A \pi-\pi$ interaction between the neighboring doubleshell cages, where the rings are parallel displaced.

These values show that there exists a favorable face-to-face $\pi$ stacking within the double-shell cage. This face-to-face stacked orientation, as evidenced by the survey based on a Cambridge Structural Database search, usually gives rise to the value of centroid-centroid contacts slightly below $3.4 \AA^{34-36}$. Under the guidance of the supramolecular recognition, a double-shell superstructure, composed of nested Archimedean and Platonic polyhedra, is ultimately formed (Fig. 2f). We thus speculate that this type of strong $\pi-\pi$ interactions promote the formation of the hierarchically organized structure as the main driving force. After nesting, the surface of $\mathbf{1}$ is almost fully enclosed (Fig. 3a) as confirmed by the $\mathrm{N}_{2}$ sorption measurements (Supplementary Fig. 9). Yet, the two triazine rings from the neighboring doubleshell cages are parallel displaced with respect to each other.

The centroid-centroid contact is of $3.577(2) \AA$, and the displacement angle is $12^{\circ}$ that is measured by the ring-centroid vector and the ring normal to one of the triazine planes (Fig. 2b). To obtain quantitative insight into the energetics of the $\pi-\pi$ stacking interactions, we performed theoretical calculations. The relative energy of two model structures (D1 and D2) was evaluated at the M062x/6-311++G(d,p) level (see the Method for computational details). As shown in Supplementary Fig. 10, D1 represents the interaction fragment between the inner and outer cages in the double-shell cage, which has the aromatic $\pi-\pi$ stacking interactions caused by the nearly overlapping s-triazine molecules. Whereas D2 represents the fragment between the double-shell cages, which has a head-to-tail phenyl-s-triazine overlap region. The calculation results show that D1 is more stable than $\mathbf{D} 2$ by $5.0 \mathrm{kcal} \mathrm{mol}^{-1}$. Note that there are eight abovementioned fragments in the complete double-shell cage, it can be expected that the aromatic $\pi-\pi$ stacking interactions between inner and outer cages become much stronger than those between adjacent double-shell cages. In addition, Supplementary Fig. 11 shows the frontier molecular orbital distribution for D1 and D2. More extended conjugation obviously contributes to the formation of such a double-shell structure.
Given that the inner and outer cages in $\mathbf{1}$ are independent and assembled by supramolecular interactions, we try to obtain their discrete objects. On the basis of our research experience about polyoxovanadate-based $\mathrm{MOPs}^{37,38}$, the inner cage, $\left(\mathrm{NH}_{2} \mathrm{Me}_{2}\right)_{12}\left[\left(\mathrm{~V}_{5} \mathrm{O}_{9} \mathrm{Cl}\right)_{6}(\mathrm{TATB})_{8}\right] \cdot\left(\mathrm{CH}_{3} \mathrm{OH}\right)_{4}(\mathbf{1 a})$, was successfully isolated in high yield by reaction of $\mathrm{VCl}_{4}, \mathrm{VOSO}_{4}$, and $\mathrm{H}_{3}$ TATB in DMF: $\mathrm{CH}_{3} \mathrm{CN}: \mathrm{CH}_{3} \mathrm{OH}(4: 1: 1 \mathrm{v} / \mathrm{v})$ at $130{ }^{\circ} \mathrm{C}$ for $48 \mathrm{~h}$ (see the "Methods" section for a detailed synthesis procedure). Singe-crystal diffraction revealed that 1a crystallized in cubic system with space group Fm-3m (Supplementary Table 1). Nevertheless, no matter how we change the reaction conditions, the outer cage cannot be isolated from the raw materials. We thus speculate that the inner cage la might induce the formation of the outer cage through template effects. To further investigate the assembly mechanism, the prefabricated 1a was directly added to the reaction system containing $\mathrm{VOSO}_{4}$ and $\mathrm{H}_{3}$ TATB in DMF: $\mathrm{CH}_{3} \mathrm{CN}(4: 1, \mathrm{v} / \mathrm{v})$ solution at $130^{\circ} \mathrm{C}$. As expected, the doubleshell structure was successfully obtained. This result suggests that the inner cage might serve as an anion template in the selfassembly, and eventually leads to the formation of the doubleshell architecture.

Selective adsorption for dye molecules. As a result of the high negative charge and the good stability of $\mathbf{1}$ and $\mathbf{1 a}$, they are anticipated to adsorb polycyclic molecules in solution. Three dye molecules with different sizes and charges were selected: Methylene Blue $\left(\mathrm{MLB}^{+}, 4.00 \times 7.93 \times 16.34 \AA\right)$, Basic Red $2\left(\mathrm{BR}^{+}\right.$, $6.43 \times 11.34 \times 13.43 \AA$ ) , and Methyl Orange $\left(\mathrm{MO}^{-}, 5.31 \times 7.25 \times\right.$ $17.39 \AA)$. Fresh crystals of 1 or $\mathbf{1 a}(15.0 \mathrm{mg})$ were immersed in 10 $\mathrm{mL}$ ethanol solution of dyes (concentration: $\left[\mathrm{MLB}^{+}\right]=5 \times 10^{-5}$ $\mathrm{M},\left[\mathrm{BR} 2^{+}\right]=2 \times 10^{-4} \mathrm{M},\left[\mathrm{MO}^{-}\right]=1 \times 10^{-4} \mathrm{M}$, respectively). The amounts of dye molecules in the supernatant was monitored by UV-Vis spectrophotometry (characteristic absorbance: $\mathrm{MLB}^{+}$ $\left.653 \mathrm{~nm}, \mathrm{BR}^{+} 545 \mathrm{~nm}, \mathrm{MO}^{-} 421 \mathrm{~nm}\right)$. As shown in Supplementary Fig. 12, the concentrations of $\mathrm{MLB}^{+}$and $\mathrm{BR} 2^{+}$in ethanol solution decreased gradually with time, but the concentration of $\mathrm{MO}^{-}$remained unchanged. These results preliminarily show that only cationic dye molecules can be selectively absorbed by $\mathbf{1}$ or $\mathbf{1 a}$. It is noteworthy that although $\mathbf{1}$ and 1a show similar adsorption abilities to $\mathrm{MLB}^{+}$(Fig. 4a), the adsorption ability of $\mathbf{1}$ for the larger BR2 ${ }^{+}$molecule is obviously lower than that of 1a, (Fig. 4b), suggesting that $\mathbf{1}$ is sensitive to the size of dye molecules. The inherent reason for this difference can be explained from the packing architectures of $\mathbf{1}$ and 1a. As shown in Supplementary Fig. 13, there are one-dimensional intersecting channels in the packing diagram of 1a with a diameter of about $8 \AA$, which can easily accommodate $\mathrm{MLB}^{+}$or $\mathrm{BR}^{+}$molecules. Nevertheless, there are no obvious pores in the packing model of $\mathbf{1}$ due to the close $\pi-\pi$ interactions between adjacent molecules; therefore only the small-sized cationic $\mathrm{MLB}^{+}$dyes could be effectively adsorbed by 1 . To further demonstrate the selective adsorption of 1 and 1a for cationic dye molecules, the crystalline samples were soaked into a DMF solution of $\mathrm{MLB}^{+}$and $\mathrm{MO}^{-}$dye molecules. $\mathrm{UV}-\mathrm{Vis}$ spectra distinctly showed that only the cationic $\mathrm{MLB}^{+}$was adsorbed by $\mathbf{1}$ and $\mathbf{1 a}$ (Fig. $4 \mathrm{c}, \mathrm{d}$ ). Thus, it can be concluded that an ion-exchange process occurred between the cationic dyes and $\left[\mathrm{NH}_{2} \mathrm{Me}_{2}\right]^{+}$cations $^{37}$.

Selective encapsulation for guest molecules of 1a. Owing to the high yield and the large void of the independent inner cage, $\mathbf{1 a}$ is highly promising as a molecular receptor for encapsulation of various guests. We first tried to include the colored organic molecule $\mathrm{C}_{60}$ in 1a. The failure of direct adsorption by placing 1a into the $\mathrm{C}_{60}$-toluene solution turned our attention to in situ cocrystallization. We added $\mathrm{C}_{60}(\sim 7.1 \AA)$ into the synthesis 
a
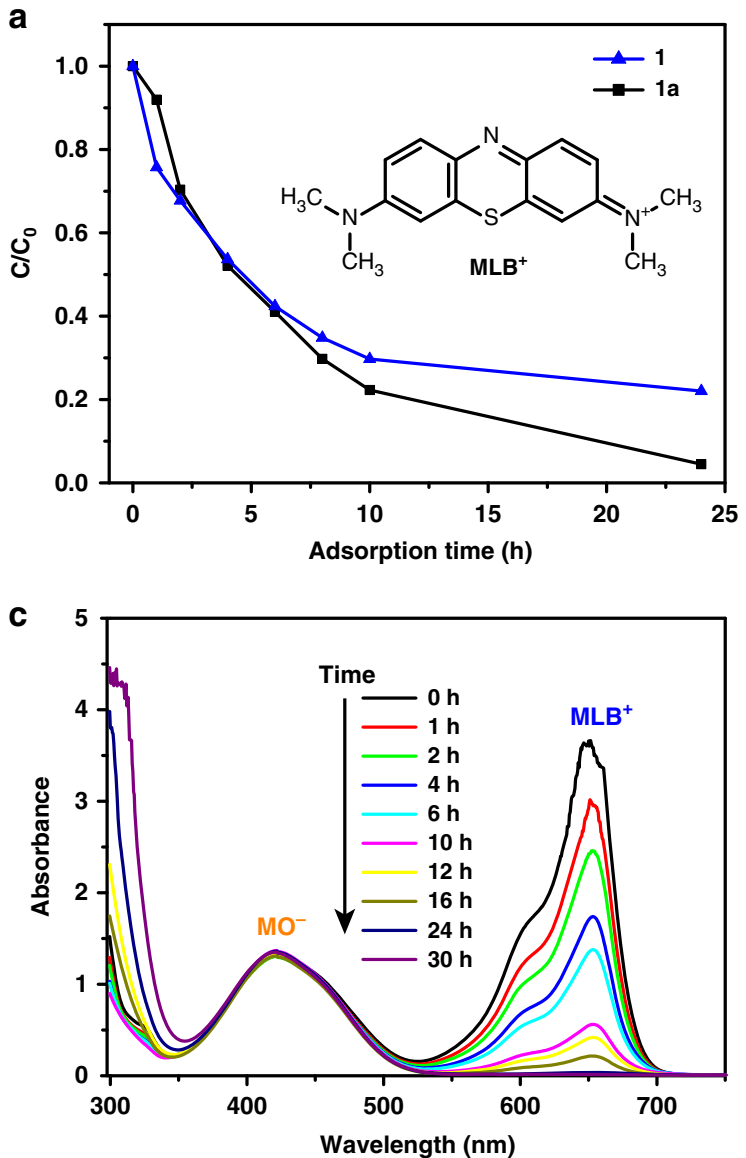

b
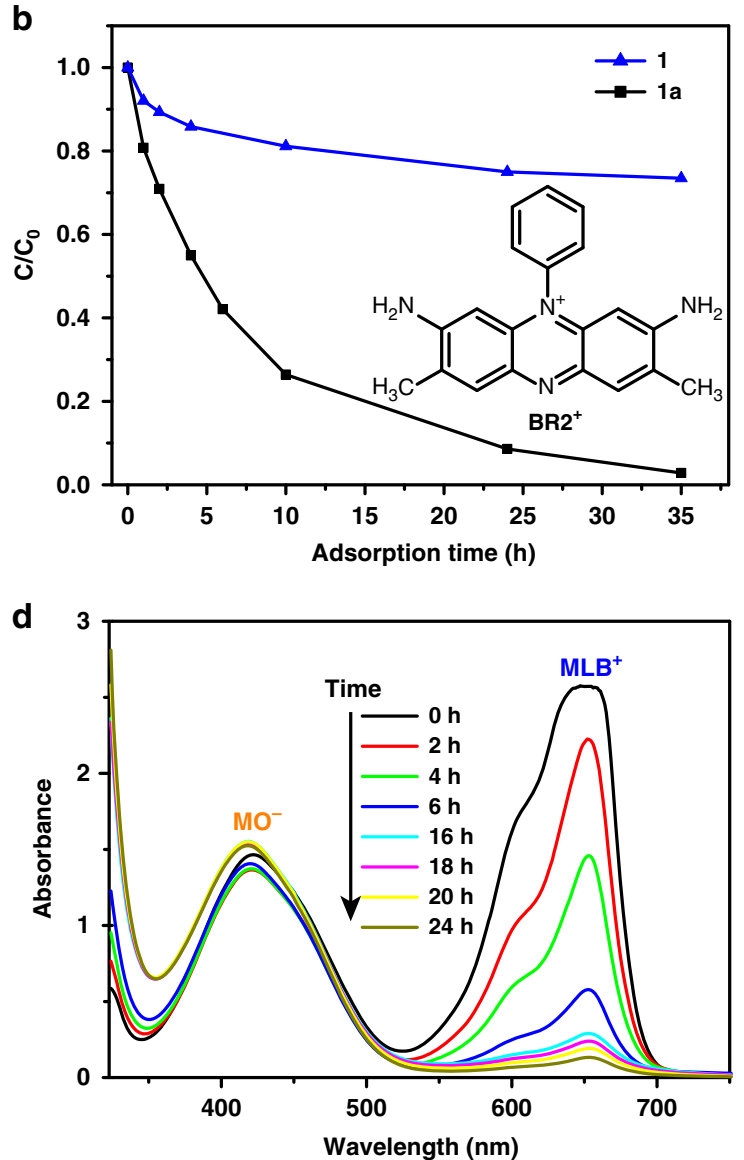

Fig. 4 Selective adsorption of $\mathbf{1}$ and $\mathbf{1 a}$ for dye molecules. $\mathbf{a}$, $\mathbf{b}$ Concentration changes of cationic dyes $\mathrm{MLB}^{+}$and $\mathrm{BR} 2^{+}$with time as determined by the UV-Vis absorbance at a selected wavelength. $\mathbf{c}, \mathbf{d}$ Temporal evolution of UV-Vis absorption spectra of a MLB+/MO ${ }^{-}$mixture in the presence of $\mathbf{1}$ and $\mathbf{1 a}$.

system of 1a. After co-crystallization for two days, the crystal color, as shown in Fig. 5a, underwent a visible change from green to dark brown, indicating the successful encapsulation of $\mathrm{C}_{60}$ molecule into the void of 1a. The inclusion of $\mathrm{C}_{60}$ in $\mathbf{1 a}$ was also probed by Raman spectroscopy with $488 \mathrm{~nm}$ excitation (Fig. $5 \mathrm{~b}$ ). The peaks of $\mathrm{H}_{\mathrm{g}}(1) 274 \mathrm{~nm}, \mathrm{~A}_{\mathrm{g}}(1) 497 \mathrm{~nm}, \mathrm{~A}_{\mathrm{g}}(2) 1465 \mathrm{~nm}$, and $\mathrm{H}_{\mathrm{g}}(8) 1576 \mathrm{~nm}$ are attributed to the vibrations of $\mathrm{C}_{60}$, in which the $A_{g}(2)$ vibration is the characteristic peak of $\mathrm{C}_{60}{ }^{39}$. What is particularly remarkable is we have got the crystal data of $\mathrm{C}_{60} @ 1 \mathbf{a}$ which provide direct evidence for $\mathrm{C}_{60}$ encapsulation (Supplementary Table 1). X-ray structural analysis clearly shows that one molecule of 1a is capable of encapsulating one $\mathrm{C}_{60}$ molecule, which is located in the center of the cavity (Fig. 5a, Supplementary Fig. 14a). Careful examination identifies that the triazine rings of the cage surface are parallel with the six-membered rings of $\mathrm{C}_{60}$, but the centroid-centroid distance of 5.960(2) $\AA$ exceeds $3.80 \AA$, the maximum acceptable contact for $\pi-\pi$ interactions (Supplementary Fig. 14b). We therefore infer the binding of $\mathrm{C}_{60}$ occurs through van der Waals forces. Meanwhile, the capability of $\mathrm{C}_{60} @ 1 \mathrm{a}$ to release $\mathrm{C}_{60}$ in toluene has also been tested. Fresh crystals $\mathrm{C}_{60} @ 1$ a were soaked in the toluene solution, and the amount of $\mathrm{C}_{60}$ molecules in the toluene was measured by UV-Vis spectrophotometry (characteristic absorbance: $540 \mathrm{~nm}$ and $600 \mathrm{~nm}$ ). As shown in Fig. $5 c$, the plots of the $C_{60}$ concentrations versus time clearly showed a continuous increase which is indicative of the gradual release of $\mathrm{C}_{60}$ molecules, and eventually the release amount reached equilibrium after $12 \mathrm{~h}$. The subsequent quantitative analyses based on the values at $540 \mathrm{~nm}$ revealed that $50 \mathrm{mg}$ of $\mathrm{C}_{60} @ 1$ a can release $4.8 \mathrm{mg}$ of $\mathrm{C}_{60}$, which is consistent with the expected ratio (the calculated mass fraction of $\mathrm{C}_{60}$ in $\mathrm{C}_{60} @ 1 \mathbf{a}$ is 1:10). At the end of the release experiments, the toluene solution changed from colorless to violet (Fig. 5d), and the crystals turned green again but were still crystalline (Fig. 5a).

Inspired by the successful encapsulation of $\mathrm{C}_{60}$ molecule, we used another two $\pi$-conjugated molecules (Supplementary Fig. 15), anthracene (flaky structure, $7.3 \times 2.8 \AA$ ) and $\mathrm{C}_{70}$ (spherical structure, $8.1 \AA$ ), to further investigate the encapsulation capacity of 1a for various guest species, so as to gain some insight into the inclusion chemistry of 1a. The co-crystallization of anthracene with $\mathrm{VOSO}_{4}, \mathrm{VCl}_{4}$ and $\mathrm{H}_{3}$ TATB yielded green product. The emission spectrum of the green product in solidstate showed the characteristic emission peaks of anthracene in the range of $400-600 \mathrm{~nm}$ with a slight blue shift (Supplementary Fig. 16), implying anthracene molecule might be trapped within 1a. The exact location of anthracene molecule was further confirmed by X-ray crystallography. Unlike the $\mathrm{C}_{60}$ molecule, anthracene molecule was located in the interstitial space between adjacent cages (Supplementary Fig. 17). This is not surprising considering that the diameter of anthracene is comparable to that of $\mathrm{C}_{60}$. However, attempts to in situ encapsulate $\mathrm{C}_{70}$ molecule turned out to be failures as demonstrated by the product color (green) and Raman spectroscopy (Supplementary Fig. 18). We attribute the failure to the relatively large size of $\mathrm{C}_{70}$. Except for the molecular size, the guest concentration may also be another factor for the binding process. The order of the solubility of these three guest molecules in the reaction system is anthracene $>\mathrm{C}_{60}>$ $\mathrm{C}_{70}$. As the solubility of $\mathrm{C}_{60}$ is superior to that of $\mathrm{C}_{70}$, the concentration of $\mathrm{C}_{60}$ in the reaction system is inevitably higher 
a

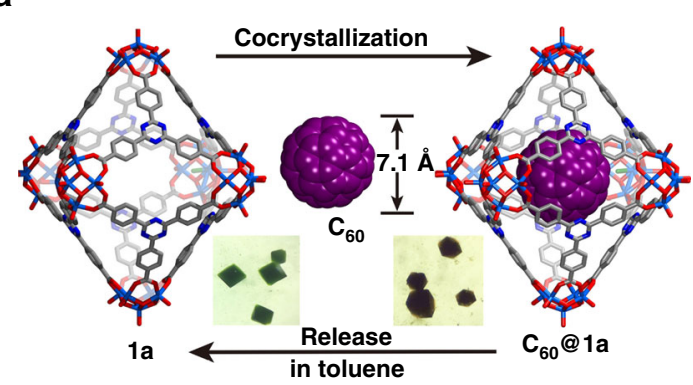

b
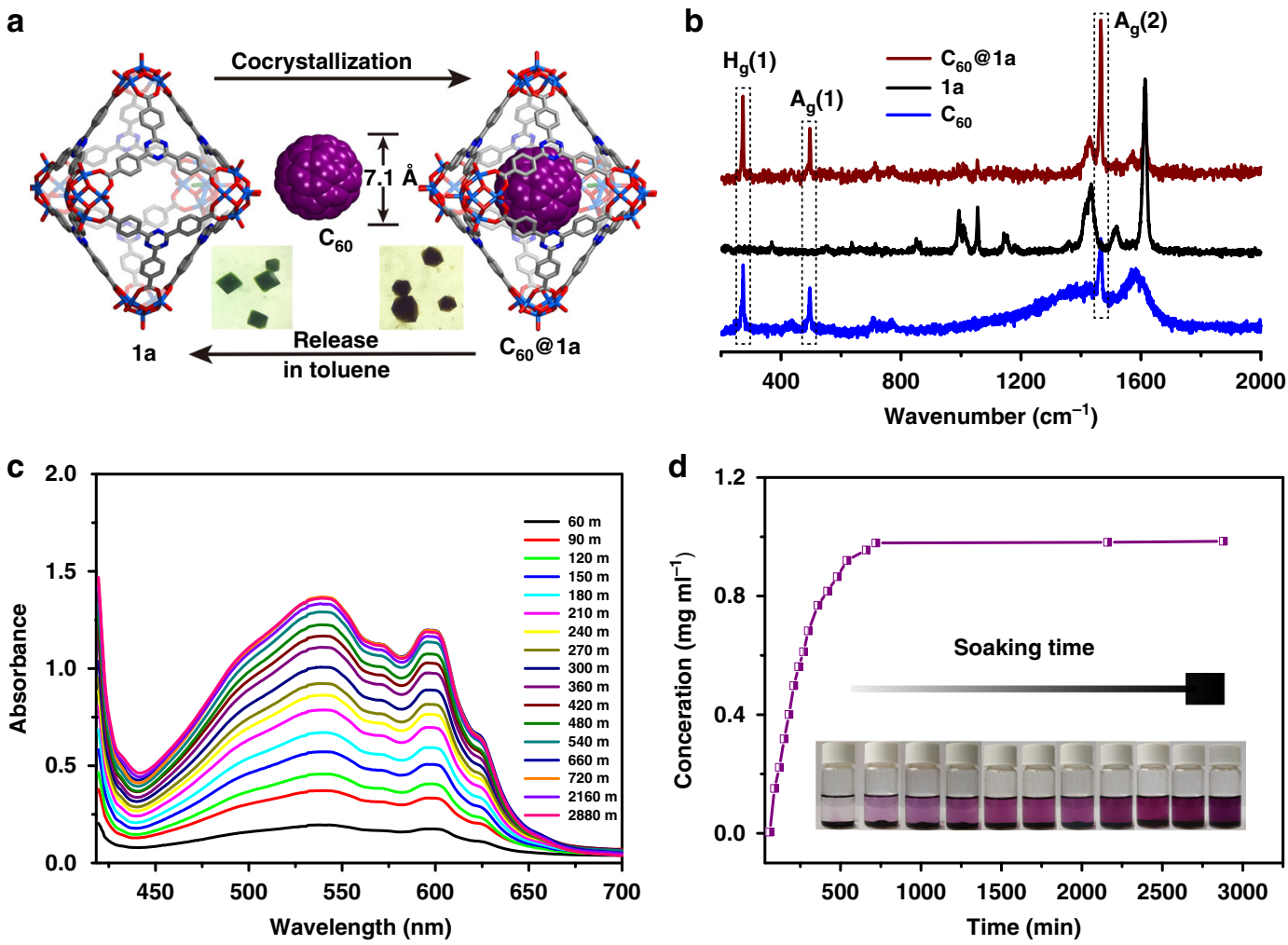

d

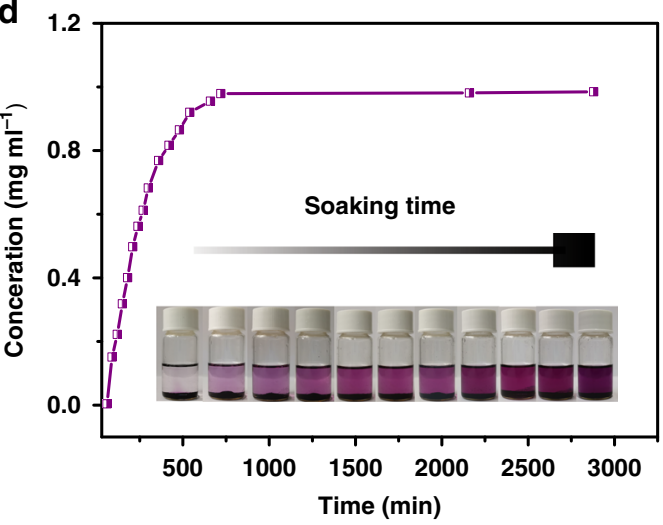

Fig. 5 The inclusion and release of $\mathbf{C}_{\mathbf{6 0}}$ molecules in 1a. a $A$ schematic illustration of the inclusion and release of $C_{60}$ molecules in $\mathbf{1 a}$. $\mathbf{b}$ Raman spectra of $\mathrm{C}_{60}$, 1a and $\mathbf{C}_{60} @ 1$ 1a. c Temporal evolution of UV-Vis absorption spectra of $\mathrm{C}_{60}$ in toluene solution. $\mathbf{d}$ Concentration changes of $\mathrm{C}_{60}$ in toluene solution with time. The inset figure shows the color evolution of the toluene solution with time.
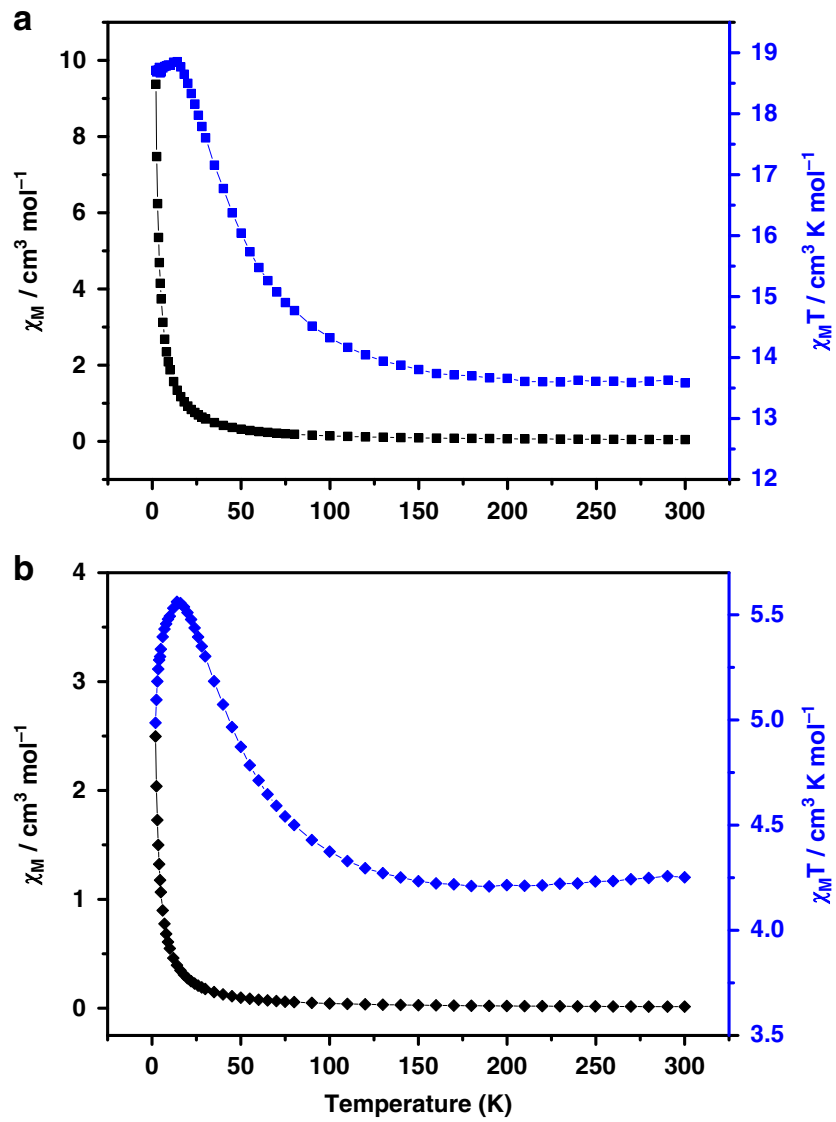

Fig. 6 Magnetic data for 1 and 1a. Temperature dependence of $\chi_{M}$ and $\chi_{M} T$ versus $T$ plots for $\mathbf{1}$ (a) and $\mathbf{1 a}(\mathbf{b})$. than that of $\mathrm{C}_{70}$, which might be a favorable dynamic factor for the formation of $\mathrm{C}_{60} @ \mathbf{1 a}$.

Magnetic properties. In view of the fact that the inner cage 1a can be isolated, the magnetic properties of $\mathbf{1}$ and $\mathbf{1 a}$ were explored to study the subtle magnetic differences originated from structure. The variable temperature magnetic susceptibilities were measured by using the fresh crystalline samples of $\mathbf{1}$ and 1a from 2 to $300 \mathrm{~K}$ under a magnetic field of 1000 Oe (Fig. 6). For 1, the room temperature $\chi_{M} T$ value is $13.6 \mathrm{~cm}^{3} \mathrm{~K} \mathrm{~mol}^{-1}$, which is consistent with the excepted value of $13.5 \mathrm{~cm}^{3} \mathrm{~K} \mathrm{~mol}^{-1}$. Whereas for 1a, the $\chi_{\mathrm{M}} T$ value of $4.2 \mathrm{~cm}^{3} \mathrm{~K} \mathrm{~mol}^{-1}$ is much lower than the excepted value $\left(9.0 \mathrm{~cm}^{3} \mathrm{~K} \mathrm{~mol}^{-1}\right)$. The magnetism is contributed by the tetravalent $\mathrm{V}^{\mathrm{IV}}$ ions rooting in outer-shell uninucleate $\mathrm{V}^{\mathrm{IV}}$ and $\left\{\mathrm{V}_{5} \mathrm{O}_{9} \mathrm{Cl}\right\}$ clusters, wherein the $\left\{\mathrm{V}_{5} \mathrm{O}_{9} \mathrm{Cl}\right\}$ includes four uncoupled $\mathrm{V}^{\mathrm{IV}}(S=1 / 2, g=2.00)^{19,40,41}$ and a central diamagnetic $\mathrm{V}^{\mathrm{V}}$ ion. As the temperature decreased from 300 to $100 \mathrm{~K}$, the changes of $\chi_{M} T$ vs. $T$ data for 1 and $\mathbf{1 a}$ trend to be similar, namely the $\chi_{M} T$ value of both $\mathbf{1}$ and 1a slightly decrease. Further lowering the temperature, the value increases rapidly reaching the maximum of $18.8 \mathrm{~cm}^{3} \mathrm{~K} \mathrm{~mol}^{-1}$ and $5.6 \mathrm{~cm}^{3} \mathrm{~K} \mathrm{~mol}^{-1}$ for $\mathbf{1}$ and $\mathbf{1 a}$, respectively, at $14 \mathrm{~K}$. Subsequently for $\mathbf{1}$, the value slightly drops to 18.6 $\mathrm{cm}^{3} \mathrm{~K} \mathrm{~mol}^{-1}$ at $2 \mathrm{~K}$. But the $\chi_{M} T$ value of 1 a decreases sharply to $4.9 \mathrm{~cm}^{3} \mathrm{~K} \mathrm{~mol}^{-1}$ at $2 \mathrm{~K}$. The continuous increase with reduction of temperature at high temperatures indicates intramolecular ferromagnetic interactions between the neighboring $\mathrm{V}^{\mathrm{IV}}$ ions $(S=1 / 2, g=2.00)$. The plot of $1 / \chi_{M}$ versus $T$ can be fitted with the Curie-Weiss law in the temperature range from 2 to $300 \mathrm{~K}$ and two positive Weiss constants $\theta=4.61$ and $3.70 \mathrm{~K}$ for $\mathbf{1}$ and $\mathbf{1 a}$ were respectively obtained (Supplementary Figs. 19-20). Both the curve and two positive $\theta$ further indicate the weak ferromagnetic coupling interactions within the double-shell cage or the independent interior cage. 


\section{Discussion}

As mentioned in the beginning, it was believed to be challenging to create nanoscale hierarchical structures. Here we not only have succeeded in assembling a fascinating cage-within-cage molecule but also several distinctive nesting characteristics have been brought to light in this case. First, a new way of using supramolecular recognition for the interconnection between inside and outside cages is demonstrated; this finding might provide a rational basis for assembling non-natural shell-like structures at the molecular level. Second, nesting first occurs in cages almost with the same size, breaking through the traditional restraints of appreciable "small vs. large" pattern. Third, the inside cage of the double-shell can be isolated as a discrete cage. Moreover, initial inclusion studies for guest molecules suggest that the inner cage can act as a molecular receptor to selectively trap the guests. We believe these out-of-ordinary nesting traits and the nesting strategy illustrated here establish new guidelines for the construction of Matryoshka-type superstructures, and we expect more such examples can be artificially synthesized in the near future.

\section{Methods}

Materials and characterization. All the reagents were obtained from commercial sources and used without further purification. PXRD measurements were recorded ranging from 5 to $50^{\circ}$ at room temperature on a Siemens D5005 diffractometer with $\mathrm{Cu}-K \alpha(\lambda=1.5418 \AA)$. The $\mathrm{C}, \mathrm{H}$ and $\mathrm{N}$ elemental analysis were conducted on a Perkin-Elmer $2400 \mathrm{CHN}$ elemental analyzer. TGA of the samples was performed using a Perkin-Elmer TG-7 analyzer heated from room temperature to $800^{\circ} \mathrm{C}$ under nitrogen at the heating rate of $10^{\circ} \mathrm{C} \mathrm{min}-1$. IR spectrum was performed in the range of $4000-400 \mathrm{~cm}^{-1}$ using $\mathrm{KBr}$ pellets on an Alpha Centaurt FT/IR spectrophotometer. The $\mathrm{N}_{2}$ sorption tests were measured on automatic volumetric adsorption equipment (Belsorp mini II). Excitation and emission spectra were obtained on a SPEX FL-2T2 spectrofluorometer equipped with a $450 \mathrm{~W}$ xenon lamp as the excitation source. Scanning electron microscopy (SEM) images were carried out using an XL-30 ESEM-FEG scanning electron microscope. XPS was performed using an Escalab 250 instrument. The UV-visible absorption spectra were obtained with a Shimadzu UV-2550 spectrophotometer. Variable temperature magnetic susceptibility data were obtained in the temperature range $2-300 \mathrm{~K}$ using a SQUID magnetometer (Quantum Design, MPMS-5) with an applied field of $1000 \mathrm{Oe}$.

\section{Synthesis of $\left(\mathrm{NH}_{2} \mathrm{Me}_{\mathbf{2}}\right)_{\mathbf{2 4}}\left\{\left[\left(\mathrm{V}_{5} \mathrm{O}_{9} \mathrm{Cl}\right)_{6}(\mathrm{TATB})_{\mathbf{8}}\right]\left[\mathrm{V}_{\mathbf{1 2}} \mathrm{O}_{\mathbf{1 2}}(\mathrm{TATB})_{\mathbf{8}}\left(\mathrm{HSO}_{\mathbf{4}}\right)_{12}\right]\right\}$} $\left(\mathbf{C H}_{\mathbf{3}} \mathbf{O H}\right)_{\mathbf{1 6}}$ (1). $\mathrm{H}_{3}$ TATB $(25.0 \mathrm{mg}, 0.057 \mathrm{mmol}), \mathrm{VOSO}_{4}(25 \mathrm{mg}, 0.15 \mathrm{mmol})$, $\mathrm{VCl}_{3}(20 \mathrm{mg}, 0.13 \mathrm{mmol})$, and $\mathrm{NaVO}_{3}(18 \mathrm{mg}, 0.1 \mathrm{mmol})$ were dissolved in DMF $(2 \mathrm{~mL}), \mathrm{CH}_{3} \mathrm{OH}(0.5 \mathrm{~mL})$, and $\mathrm{CH}_{3} \mathrm{CN}(0.5 \mathrm{~mL})$. Then the mixture was sealed in a Parr Teflon-lined stainless steel vessel and heated at $130{ }^{\circ} \mathrm{C}$ for two days and gradually cooled to room temperature. Dark green crystals were obtained, washed with DMF, and dried in air (yield: $\sim 43 \%$, based on $\mathrm{H}_{3}$ TATB). Elemental analysis (\%) for $\mathrm{C}_{448} \mathrm{H}_{460} \mathrm{Cl}_{6} \mathrm{~N}_{72} \mathrm{O}_{226} \mathrm{~S}_{12} \mathrm{~V}_{42}$ : Calcd: C, 40.75; H, 3.51; N, 7.63. Found: $\mathrm{C}$, 40.58; H, 3.75; N, 7.32. IR (KBr, cm $\left.{ }^{-1}\right): 3424(\mathrm{~s}), 1708(\mathrm{~s}), 1582(\mathrm{~m}), 1518(\mathrm{~m})$, 1465(w), 1402(m), 1360(s), 1111(s), 974(s), 883(w), 827(m), 770(s), 695(w), 619(s), $532(\mathrm{~s})$.

\section{Synthesis of $\left(\mathbf{N H}_{\mathbf{2}} \mathbf{M e}_{\mathbf{2}}\right)_{\mathbf{1 2}}\left[\left(\mathbf{V}_{\mathbf{5}} \mathbf{O}_{\mathbf{9}} \mathbf{C l}\right)_{\mathbf{6}}(\mathrm{TATB})_{\mathbf{8}}\right] \cdot\left(\mathbf{C H}_{\mathbf{3}} \mathrm{OH}\right)_{\mathbf{4}} \mathbf{( 1 a )} . \mathrm{H}_{3}$ TATB} $(25.0 \mathrm{mg}, 0.057 \mathrm{mmol})$, $\mathrm{VOSO}_{4}(25 \mathrm{mg}, 0.15 \mathrm{mmol})$, and $\mathrm{VCl}_{4}(20 \mathrm{mg}, 0.104$ $\mathrm{mmol})$ were dissolved in DMF $(2 \mathrm{~mL}), \mathrm{CH}_{3} \mathrm{OH}(0.5 \mathrm{~mL})$, and $\mathrm{CH}_{3} \mathrm{CN}(0.5 \mathrm{~mL})$. Then the mixture was placed in a Teflon-lined stainless vessel, and heated to $130{ }^{\circ} \mathrm{C}$ for two days. After slowly cooling to room temperature, green crystals were obtained, washed with DMF and dried in air (yield: $\sim 69 \%$, based on $\mathrm{H}_{3}$ TATB). Elemental analysis (\%) for $\mathrm{C}_{220} \mathrm{H}_{208} \mathrm{Cl}_{6} \mathrm{~N}_{36} \mathrm{O}_{106} \mathrm{~V}_{30}$ : Calcd: $\mathrm{C}, 38.89 ; \mathrm{H}, 3.08 ; \mathrm{N}$, 7.42. Found: C, 38.78; H, 3.25; N, 7.27.IR $\left(\mathrm{KBr}, \mathrm{cm}^{-1}\right): 3410(\mathrm{~s}), 1713(\mathrm{~s}), 1556(\mathrm{~m})$, 1519(m), 1483(w), 1403(m), 1359(s), 1257(w), 1103(w), 987(s), 881(s), 824(s), 771 (m), 698(s), 588(w), 551(w). 1a can be obtained in a wide range of temperatures. As the reaction temperature is decreased to $90^{\circ} \mathrm{C}$, 1a still can be obtained, but the yield drops significantly.

Synthesis of 1 from 1a. In a $15 \mathrm{~mL}$ Teflon-lined stainless vessel, prefabricated crystals of 1a $(10 \mathrm{mg})$, VOSO $_{4}(20 \mathrm{mg})$, and $\mathrm{H}_{3}$ TATB $(20 \mathrm{mg})$ were dissolved in DMF $(2 \mathrm{~mL})$ and $\mathrm{CH}_{3} \mathrm{CN}(0.5 \mathrm{~mL})$. The mixture was heated at $130{ }^{\circ} \mathrm{C}$ for $48 \mathrm{~h}$ and gradually cooled to room temperature to obtain dark green crystals of $\mathbf{1}$ (yield: $\sim 52 \%$, based on $\mathrm{H}_{3}$ TATB).

Synthesis of $\mathbf{C}_{\mathbf{6 0}} @ \mathbf{1 a}$. The procedure is similar to that of 1a, except that extra $5 \mathrm{mg}$ $\mathrm{C}_{60}$ and $1 \mathrm{~mL}$ toluene was added into the reaction system. After cooling to the room temperature, dark brown crystals were obtained and washed with toluene twice to give the pure samples (yield: $\sim 53 \%$, based on $\mathrm{H}_{3} \mathrm{TATB}$ ). Elemental analysis (\%) for $\mathrm{C}_{280} \mathrm{H}_{208} \mathrm{Cl}_{6} \mathrm{~N}_{36} \mathrm{O}_{106} \mathrm{~V}_{30}$, Calcd: C, 44.75; H, 2.79; N, 6.71. Found: C, 44.54; $\mathrm{H}, 2.64 ; \mathrm{N}, 6.57$.

Procedure for trying to encapsulate $\mathbf{C}_{\mathbf{7 0}}$ in $\mathbf{1 a}$. The procedure is similar to the methods mentioned above for the synthesis of $\mathrm{C}_{60} @ 1$ a, except that equal quality of $\mathrm{C}_{70}$ instead of $\mathrm{C}_{60}$. Unfortunately, after cooling to the room temperature, just the green crystals of 1a were obtained. We also tried to change the amount of $\mathrm{C}_{70}$ but still got the same results.

Synthesis of anthracene@1a. The procedure is similar to that of 1a, except that extra $15 \mathrm{mg}$ anthracene was added into the reaction system. After cooling to the room temperature, green crystals were obtained, washed with DMF twice to give the pure samples (yield: $\sim 60 \%$, based on $\mathrm{H}_{3}$ TATB).

$\mathbf{C}_{60}$ extraction from $\mathbf{C}_{60} @ 1$ a. Inclusion crystals $\mathrm{C}_{60} @ 1 \mathbf{1 a}$ were immersed into 5.0 $\mathrm{mL}$ of toluene (spectroscopic grade). The resulting suspension was stand at room temperature without crashing crystals. The concentration of the extracted $\mathrm{C}_{60}$ was measured by UV-Vis absorption spectra of the supernatant (detection wavelength: $540 \mathrm{~nm})$.

Single-crystal X-ray diffraction. A summary of the crystallographic data and structural refinements for 1, 1a and $\mathrm{C}_{60} @ \mathbf{1 a}$ and anthracene@1a are given in Supplementary Table 1 . All crystallographic data were collected at $173 \mathrm{~K}$ on a Bruker D8-Venture diffractometer with graphite-monochromated Mo K $\alpha$ radiation $(\lambda=0.71073 \AA)(\mathbf{1 a})$ and $\mathrm{Cu} \mathrm{K} \alpha$ radiation $(\lambda=1.5418 \AA)\left(\mathbf{1}, \mathrm{C}_{60} @ \mathbf{1 a}\right.$ and anthracene@1a). The data were collected using the program APEX 3 and processed using the program SAINT routine in APEX 3. The structures were solved by direct methods with SHELXS-2014 and refined with SHELXL-2014 program $^{42,43}$. All non-hydrogen atoms, except disordered $\mathrm{C}_{60}$ and anthracene, were refined in anisotropic approximation. Hydrogen atoms were refined in geometrically calculated positions using the "riding model" with $U_{i s o}(H)=1.2 U_{i s o}(C)$. The large cell volume and high crystal symmetry did not allow refining the disordered solvent molecules and dimethylamine counter cations within the crystal lattices, therefore, SQUEEZE routines in PLATON were used for $\mathbf{1}, \mathbf{1 a}$, and $\mathrm{C}_{60} @ \mathbf{1 a}$ to generate the reflection intensities with subtracted solvent contributions ${ }^{44}$. For 1 , the sulfate groups were disordered, so the restraints DFIX and SADI were used to confine the bond length of sulfate groups. SIMU and ISOR constraints were used for organic ligands and partial metal centers with large thermal motions. For $\mathrm{C}_{60} @ 1$ a, the $\mathrm{C}_{60}$ molecule was disordered, so the restraints SADI, FLAT, SIMU, RIGU, ISOR were applied to model the geometry of $\mathrm{C}_{60}$, the ISOR constraints were used for dimethylamine cation with large thermal motion. For anthracene@1a, the anthracene and dimethylamine molecule were disordered, so the restraints SADI, FLAT, RIGU, and SIMU were used to confine the geometry of anthracene molecule, DFIX, ISOR, and SIMU constraints were used for dimethylamine cation with large thermal motion.

Computational details. Two model structures D1 and D2 were extracted from crystal structures. Constraint optimization was performed at the M062 $\mathrm{x}^{45} / 6-31 \mathrm{G}$ (d) level to determine the position of hydrogen atoms. Electronic energies were evaluated at the M062x/6-311++G(d,p) level. These calculations were carried out with the Gaussian 09 program 46

\section{Data availability}

The X-ray crystallographic data for structures reported in this article have been deposited at the Cambridge Crystallographic Data Centre (CCDC), under deposition number CCDC 1864118 (1), 1864121 (1a), 1864122 (C60@1a), 2003560 (anthracene@1a). These data can be obtained free of charge from The Cambridge Crystallographic Data Centre via www.ccdc.cam.ac.uk/data_request/cif. All relevant data supporting the findings of this study are available from the corresponding authors on request.

Received: 7 January 2020; Accepted: 24 July 2020;

Published online: 14 August 2020

\section{References}

1. Liu, Y. Z., Hu, C. H., Comotti, A. \& Ward, M. D. Supramolecular Archimedean cages assembled with 72 hydrogen bonds. Science 333, 436-440 (2011).

2. Han, M. X., Engelhard, D. M. \& Clever, G. H. Self-assembled coordination cages based on banana-shaped ligands. Chem. Soc. Rev. 43, 1848-1860 (2014)

3. Luo, D., Wang, X. Z., Yang, C., Zhou, X. P. \& Li, D. Self-assembly of chiral metal-organic tetartoid. J. Am. Chem. Soc. 140, 118-121 (2018). 
4. Chakrabarty, R., Mukherjee, P. S. \& Stang, P. J. Supramolecular coordination: self-assembly of finite two- and three-dimensional ensembles. Chem. Rev. 111, 6810-6918 (2011).

5. Smulders, M. M. J., Riddell, I. A., Browne, C. \& Nitschke, J. R. Building on architectural principles for three-dimensional metallosupramolecular construction. Chem. Soc. Rev. 42, 1728-1754 (2013).

6. Eddaoudi, M. et al. Porous metal-organic polyhedra: $25 \AA$ cuboctahedron constructed from $12 \mathrm{Cu}_{2}\left(\mathrm{CO}_{2}\right)_{4}$ paddle-wheel building blocks. J. Am. Chem. Soc. 123, 4368-4369 (2001).

7. Caspar, D. L. D. \& Klug, A. Physical principles in the construction of regular viruses. Cold Spring Harb. Symp. Quant. Biol. 27, 1-24 (1962).

8. Baker, T. S., Olson, N. H. \& Fuller, S. D. Adding the third dimension to virus life cycles: three-dimensional reconstruction of icosahedral viruses from cryo-electron micrographs. Mol. Biol. Rev. 63, 862-922 (1999).

9. Lawson, D. M. et al. Solving the structure of human $\mathrm{H}$-ferritin by genetically engineering intermolecular crystal contacts. Nature 349, 541-544 (1991).

10. Radhakrishnan, U., Schweiger, M. \& Stang, P. J. Metal-directed formation of three-dimensional $\mathrm{M}_{3} \mathrm{~L}_{2}$ trigonal-bipyramidal cages. Org. Lett. 3, 3141-3143 (2001).

11. Olenyuk, B., Whiteford, J. A., Fechtenkötter, A. \& Stang, P. J. Self-assembly of nanoscale cuboctahedra by coordination chemistry. Nature 398, 796-799 (1999).

12. Yu, S. Y., Kusukawa, T., Biradha, K. \& Fujita, M. Hydrophobic assembling of a coordination nanobowl into a dimeric capsule which can accommodate up to six large organic molecules. J. Am. Chem. Soc. 122, 2665-2666 (2000).

13. Sun, Q. F., Sato, S. \& Fujita, M. An $\mathrm{M}_{18} \mathrm{~L}_{24}$ stellated cuboctahedron through post-stellation of an $\mathrm{M}_{12} \mathrm{~L}_{24}$ core. Nat. Chem. 4, 330-333 (2012).

14. Sun, Q. F. et al. Self-assembled $\mathrm{M}_{24} \mathrm{~L}_{48}$ polyhedra and their sharp structural switch upon subtle ligand variation. Science 328, 1144-1147 (2010).

15. Casjens, S. in Virus Structure And Assembly, (Jones and Bartlett, Boston, MA, 1985).

16. Grimes, J. M. et al. The atomic structure of the bluetongue virus core. Nature 395, 470-478 (1998).

17. Wikoff, W. R. et al. Topologically linked protein rings in the bacteriophage HK97 capsid. Science 289, 2129-2133 (2000).

18. Wang, X. et al. Assembled molecular face-rotating polyhedra to transfer chirality from two to three dimensions. Nat. Commun. 7, 12469 (2016).

19. Su, K., Wu, M., Yuan, D. \& Hong, M. Interconvertible vanadium-seamed hexameric pyrogallol[4]arene nanocapsules. Nat. Commun. 9, 4941 (2018).

20. Bilbeisi, R. A., Ronson, T. K. \& Nitschke, J. R. A self-assembled $\left[\mathrm{Fe}^{\mathrm{II}}{ }_{12} \mathrm{~L}_{12}\right]$ capsule with an icosahedral framework. Angew. Chem. Int. Ed. 52, 9027-9030 (2013).

21. Fujita, D. et al. Self-assembly of tetravalent Goldberg polyhedra from 144 small components. Nature 540, 563-566 (2016).

22. $\mathrm{Bu}, \mathrm{F}$. et al. Two zeolite-type frameworks in one metal-organic framework with $\mathrm{Zn}_{24} @ \mathrm{Zn}_{104}$ cube-in-sodalite architecture. Angew. Chem. Int. Ed. 51, 8538-8541 (2012).

23. Zheng, S. T. et al. Multicomponent self-assembly of a nested $\mathrm{Co}_{24} @ \mathrm{Co}_{48}$ metal-organic polyhedral framework. Angew. Chem. Int. Ed. 50, 8034-8037 (2011).

24. Tian, D. et al. A mixed molecular building block strategy for the design of nested polyhedron metal-organic frameworks. Angew. Chem. Int. Ed. 53, 837-841 (2014).

25. Zheng, S. T. et al. Pore space partition and charge separation in cage-within-cage indium-organic frameworks with high $\mathrm{CO}_{2}$ uptake. J. Am. Chem. Soc. 132, 17062-17064 (2010).

26. Lian, T. T., Chen, S. M., Wang, F. \& Zhang, J. Metal-organic framework architecture with polyhedron-in-polyhedron and further polyhedral assembly. CrystEngComm 15, 1036-1038 (2013).

27. Sun, Q. F., Murase, T., Sato, S. \& Fujita, M. A sphere-in-sphere complex by orthogonal self-assembly. Angew. Chem. Int. Ed. 50, 10318-10321 (2011).

28. Sun, B. et al. From ring-in-ring to sphere-in-sphere: self-assembly of discrete 2D and 3D architectures with increasing stability. J. Am. Chem. Soc. 137, 1556-1564 (2015).

29. Bhat, I. A., Samanta, D. \& Mukherjee, P. S. A Pd 24 pregnant molecular nanoball: self-templated stellation by precise mapping of coordination sites. $J$. Am. Chem. Soc. 137, 9497-9502 (2015).

30. Byrne, K. et al. Ultra-large supramolecular coordination cages composed of endohedral Archimedean and Platonic bodies. Nat. Commun. 8, 15268 (2017).

31. Brown, I. D. \& Altermatt, D. Bond-valence parameters obtained from a systematic analysis of the inorganic crystal structure database. Acta Crystallogr. Sect. B: Struct. Sci. 41, 244-247 (1985).

32. O'Keeffe, M. Design of MOFs and intellectual content in reticular chemistry: a personal view. Chem. Soc. Rev. 38, 1215-1217 (2009).

33. Pennington, W. T. Diamond program-crystal and molecular structure visualization. J. Appl. Cryst. 32, 1028-1029 (1999).
34. Biedermann, F. \& Schneider, H. J. Experimental binding energies in supramolecular complexes. Chem. Rev. 116, 5216-5300 (2016).

35. Janiak, C. A critical account on $\pi-\pi$ stacking in metal complexes with aromatic nitrogen-containing ligands. Dalton Trans. 29, 3885-3896 (2000).

36. Hoeben, F. J. M., Jonkheijm, P., Meijer, E. W. \& Schenning, A. P. H. J. About supramolecular assemblies of $\pi$-conjugated systems. Chem. Rev. 105, 1491-1546 (2005)

37. Zhang, $\mathrm{Y}$. T. et al. Self-Assembly of Goldberg polyhedra from a concave $\left[\mathrm{WV}_{5} \mathrm{O}_{11}\left(\mathrm{RCO}_{2}\right)_{5}\left(\mathrm{SO}_{4}\right)\right]^{3-}$ building block with 5-fold symmetry. J. Am. Chem. Soc. 140, 17365-17368 (2018).

38. Gong, Y. R. et al. Bottom-up construction and reversible structural transformation of supramolecular isomers based on large truncated tetrahedra. Angew. Chem. Int Ed. 58, 780-784 (2019).

39. Chae, H. K. et al. A route to high surface area, porosity and inclusion of large molecules in crystal. Nature 427, 523-527 (2004).

40. Aronica, C. et al. A mixed-valence polyoxovanadate (III, IV) cluster with a calixarene cap exhibiting ferromagnetic V(III)-V(IV) interactions. J. Am. Chem. Soc. 130, 2365-2371 (2008).

41. Cao, J. P. et al. Lewis acid dominant windmill-shaped $\mathrm{V}_{8}$ clusters: a bifunctional heterogeneous catalyst for $\mathrm{CO}_{2}$ cycloaddition and oxidation of sulfides. J. Am. Chem. Soc. 141, 19487-19497 (2019).

42. Sheldrick, G. M. A short history of SHELX. Acta Crystallogr. A 64, 112-122 (2008).

43. Sheldrick, G. M. Crystal structure refinement with SHELXL. Acta Crystallogr. C. 71, 3-8 (2015).

44. Spek, A. L. Structure validation in chemical crystallography. Acta Crystallogr. D. 65, 148-155 (2009).

45. Zhao, Y. \& Truhlar, D. G. The M06 suite of density functionals for main group thermochemistry, thermochemical kinetics, noncovalent interactions, excited states, and transition elements: two new functionals and systematic testing of four M06-class functionals and 12 other functionals. Theor. Chem. Acc. 120, 215-241 (2008).

46. Frisch, M. J. et al. Gaussian 09, Revision D. 01 (Gaussian Inc., 2009).

\section{Acknowledgements}

This work was supported financially by the NSFC of China (No. 21671034, 21771035).

\section{Author contributions}

X.W. and Z.S. conceived and designed the experiment. H.G. conducted synthesis and characterization. N.X. solved the crystal structure. C.Q., C.S., and X.W. co-wrote the manuscript. All the authors contributed to the analysis of the results.

\section{Competing interests}

The authors declare no competing interests.

\section{Additional information}

Supplementary information is available for this paper at https://doi.org/10.1038/s41467020-17989-6.

Correspondence and requests for materials should be addressed to X.W.

Peer review information Nature Communications thanks the anonymous reviewer(s) for their contribution to the peer review of this work.

Reprints and permission information is available at http://www.nature.com/reprints

Publisher's note Springer Nature remains neutral with regard to jurisdictional claims in published maps and institutional affiliations.

Open Access This article is licensed under a Creative Commons Attribution 4.0 International License, which permits use, sharing, adaptation, distribution and reproduction in any medium or format, as long as you give appropriate credit to the original author(s) and the source, provide a link to the Creative Commons license, and indicate if changes were made. The images or other third party material in this article are included in the article's Creative Commons license, unless indicated otherwise in a credit line to the material. If material is not included in the article's Creative Commons license and your intended use is not permitted by statutory regulation or exceeds the permitted use, you will need to obtain permission directly from the copyright holder. To view a copy of this license, visit http://creativecommons.org/ licenses/by/4.0/.

(C) The Author(s) 2020 